\title{
Factors affecting the utilization of prevention of mother-to-child transmission of HIV services in Anambra South, Nigeria
}

\author{
Chinyere E. Onalu', Agha A.Agha', Yemi Adewoyin ${ }^{2}$, Samuel O. Ebimgbo' \\ \& Uzoma O. Okoye ${ }^{1}$ \\ ${ }^{1}$ Department of Social Work, Faculty of the Social Sciences, University of Nigeria, \\ Nsukka, Enugu State, Nigeria. \\ ${ }^{2}$ Department of Geography, Faculty of the Social Sciences, University of Nigeria, Nsukka \\ Enugu State, Nigeria \\ Email: ali.agha@unn.edu.ng
}

\begin{abstract}
Background: In spite huge leaps in combating the spread and transmission of HIV globally, Nigeria still ranks high in the incidence of HIV among children. The study investigates the factors affecting the utilization of prevention of mother-to-child transmission (PMTCT) of HIV services in Anambra South.

Data source and Method: Data from 5 I5 HIV positive women of child bearing age were collected using a structured questionnaire. The data sets were subjected to chi square and binary logistic regression analysis.

Result: The results show that $86 \%$ of the respondents were aware of the PMTCT strategies while marital status $(69.8 \%)$, age $(70.7 \%)$ and place of residence $(52.1 \%)$ were found to affect the uptake and utilization of PMTCT services.

Conclusion: Evidence from the study drew attention to the need for government, social workers and healthcare providers to rise to their responsibilities in encouraging HIV women of reproductive age to utilize PMTCT services in order to achieve African Union Agenda 3.
\end{abstract}

Keywords: Mother-to-Child Transmission, PMTCT Utilization, HIV in Nigeria, Anambra South, Social Worker

\section{Introduction}

Nigeria has the highest number of children acquiring HIV in the world (Cohen, 2018). It is estimated that 36,000 Nigerian children were newly infected with HIV/AIDS in 2016, higher than that of any other country in the world (Cohen, 20I8). In Nigeria, 10\% of all HIV infections are as a result of MTCT and more than 85,000 infants in Nigeria are at risk of HIV transmission from their mothers every year (Punch, 2014). Nigeria accounts for about $30 \%$ of the global burden of MTCT; with an MTCT rate of about $32 \%$ and 75,000 new infant HIV infections per annum (World Health Organization [WHO], 20I0; WHO, 20I I; Ezeanolue et al, 20I3). While several other sub Saharan African countries like Botswana, Ethiopia, Ghana, Malawi, Namibia, South Africa and Zambia have all witnessed a $50 \%$ decline in incidence rate of HIV in children, the United -Republic of Tanzania and Zimbabwe are almost achieving elimination of MTCT (Tobore, 20I3). Going by this record Nigeria is still far from the 2015 target of global elimination of MTCT (Mfrekemfon \& Rimande-Joel, 20I5).

Mother to child transmission (MTCT), or vertical transmission of HIV infection, is the transmission of the virus from an infected mother to her child during pregnancy, labour, delivery or breastfeeding (Abajobir \& Zeleke, 2013; Joint United Nations Programme on HIV/AIDS [UNAIDS], 2008). The elimination of new HIV infections among children can be achieved through the Prevention of Mother to Child Transmission (PMTCT) (UNICEF, 2017). PMTCT of HIV is a global interventional program initiated by the United Nations to protect the children of the world from the scourge of the HIV pandemic (UN, 2002). The past decade has witnessed tremendous global progress in reducing mother-to-child transmission of HIV, the leading cause of HIV infection in children (Global health learning organization, 2017). Effective interventions exist to virtually eliminate MTCT during pregnancy, labour, delivery, and breastfeeding (UNICEF, 20I6). Yet, MTCT remains a challenge; the majority of the estimated 150,000 new HIV infections in children were from MTCT (UNAIDS, 2016). For women to take advantage of measures to reduce transmission, they need to know about MTCT and utilization of services designed for PMTCT of HIV among pregnant 
women (Hamdela, Zekiewos \& Workneh, 20I4). Nonetheless, Nigeria remains one of the 22 focus countries of the Global Plan to Eliminate MTCT (UNAIDS, 20I3). Therefore, there is need to identify factors that determine utilization prevention of mother to child transmission of HIV services in Anambra south.

The declaration that Nigeria has more HIVinfected babies than anywhere in the World attest to the precarious position of the country in terms of the uptake of PMTCT services (NACA, 20I8). The Nigeria National AIDS Control Agency (NACA) has rightly identified the challenges facing PMTCT to include poor uptake despite the availability of PMTCT services and commodities amongst others (NACA, 20I2). Some of the challenges included poor adherence to antiretroviral therapy, poor linkage between mother-child pairs and post-natal healthcare services, low early infant diagnosis coverage, low pediatric ART coverage, poor community involvement, socio-cultural influences, and inadequate family planning counseling, (Adetokunboh \& Oluwasanu, 20I6).

As a region, Sub-Saharan Africa is relatively lagging behind other regions of the world as far as 'inclusive' development is concerned. The region is yet to recognize the necessity for the development of a social policy framework which combines economic dynamism with an active role for government in the provision of basic social and other services at local and national levels (Kalule-Sabiti, Amoateng \& Ngake, 20I4). That is why the African Union (AU) Agenda 2063 is a statement of ambition, though with the vision to build an integrated, prosperous and peaceful Africa, an Africa driven and managed by its own citizens and representing a dynamic force in the international arena. The AU 2063 Agenda, broken into seven point aspirations reflect the desire of Africans for prosperity and well-being, for unity and integration, for a continent of free citizens and expanded horizons, with freedom from conflict and improved human security; an Africa of strong identity, culture and values, as well as a strong and influential partner on the global stage making equal contribution to human progress and welfare (African Union Commission, 2014). Each aspiration in the $A U$ Agenda has specific targets and focal areas that will help measure its attainment. The first aspiration on the agenda reads: A Prosperous Africa based on Inclusive Growth and Sustainable Development. The sub-targets include:

- African people have a high standard of living and quality of life and well-being.

- Well educated citizens and skills revolution underpinned by science, technology and innovation for a knowledge society
- Citizens are healthy, well-nourished and have long life spans

- Cities and other settlements are modernized and people have access to all the basic necessities of life

- Economies are structurally transformed to create shared growth and decent jobs for all

- Modern agriculture for increased production, productivity and value addition contribute to farmer and national prosperity

- The continent while attaining prosperity maintains healthy ecosystems and preserves the African and global environment.

This study is substantiated by the targets I \& 3 of aspiration I of the AU Agenda 2063 that focuses on building a continent where African people have a high standard of living and quality of life and well-being, and where Citizens are healthy, well-nourished and have long life spans. By 2063, every citizen will have full access to affordable and quality health care services. Africa would have rid itself of all the neglected tropical diseases (NTDs), fully brought under control all communicable and infectious diseases; put in place systems for significantly reduced non-communicable and lifestyle changes related diseases and reduced to zero deaths from HIV/AIDS, Malaria and Tuberculosis. The African population of 2063 will be a healthy and well nutrition enjoying a life expectancy of above 75 years (AU, 2014). The attainment of these targets should be inclusive and no country of Africa should be left behind, and while setting goals has never been a challenge to African development, it is the implementation and pursuit of these goals that usually pose serious problems. If the AU Agenda 2063 will be achieved in Nigeria as it relates to HIV/AIDS, the implementation of PMTCT should be given full attention.

Studies have shown that despite the high burden of HIV/AIDS in Nigeria, implementation of PMTCT programmes remain poor in the country (Arisegi, Awosa, Abdulsamad, Adamu, Isah \& Morah, 2017). In $20 \mathrm{II}$, it was estimated that only $17.1 \%$ of HIV infected pregnant women in Nigeria received antiretroviral (ARV) drug treatment and it was far below the $80 \%$ universal access that was recommended for the elimination of MTCT transmission of HIV (NACA, 20I2; WHO, 20I0). In addition, reports show poor utilization of PMTCT services among pregnant women in Nigeria, even where they are available (NACA, 2012). Nigeria's PMTCT programme implementation has been challenging especially in rural areas (Agudu et al, 2017). Utilization of maternal health services, including PMTCT, is low in rural communities, where only $47 \%$ of women access skilled antenatal care (ANC), compared with $86 \%$ of their urban counterparts 
(United Nations, 20I5; NPC, 2013). Factors influencing utilization of PMTCT of HIV services in Nigeria have been discussed in some states like Bauchi, Abia, Oyo etc to include literacy, awareness, social stigmatization, socio-cultural factors amongst others - (Arulogun et al, 2007; Balogun \& Owoaje, 2015; Eze \& Aniwada, 2016; Ibrahim, Mohammed \& Umar, 2016; Iwelunmor et al. 2014; Michael \& Ogbodo, 20/3). This study becomes imperative in the context of Anambra to delineate the factors affecting the uptake of PMTCT of HIV services; and it is against this background that this study aims to answer the following questions: (a) Are HIV positive women aware of intervention strategies for prevention of mother to child transmission of HIV/AIDS? (b) What are the contextual determinants of PMTCT utilization in Anambra?

\section{Literature review}

Nigeria has the highest paediatric HIV burden worldwide (WHO, 20I0). There were 56,68I HIV positive births in the country in 2009 contributing $15.3 \%$ of the 370,000 global new paediatric HIV infections for that year (NACA, 20I2). The initiative for the establishment of PMTCT in Nigeria started with the inauguration of the PMTCT National Task Team in 2000 and actual services in Nigeria commenced as a pilot project in 2002 (Agboghoroma, Sagay \& Ikechebelu, 2013). In 2004, PMTCT services received a boost in Nigeria when the UNAIDS/WHO recommended routine HIV testing of pregnant women with the right to refuse in order to increase access to PMTCT and ARV therapy in resource limited countries (WHO \& UNICEF, 2007). Efforts have been made to scale up these services over the years but these efforts have to be greatly intensified as indicators from the 2008 National Demographic Health Survey still showed poor utilization of PMTCT services among Nigerian pregnant women even when they were made available (NPC, 2009).Currently, health policies on PMTCT services in Nigeria and Africa have emphasized the importance of preventive care at the primary health care level (Amoran, Salami \& Oluwole, 20I2). However, coverage of PMTCT service in this region remains low with an estimated coverage of $25 \%$ on average (WHO, UNAIDS \& UNICEF, 2009). This implies that weak PMTCT services and low coverage rates are leaving MTCT transmission of HIV largely unabated which results to high number of new paediatric infections (Amoran et al., 20I2). The challenges that need to be surmounted include insufficient PMTCT services especially in the rural communities and even health facilities located in high prevalence areas. There is also the issue of low community involvement in
PMTCT programme which is averse to programme ownership and sustainability (Moses, Chama, Udo \& Omotora, 2008).

Issues of public health always take a collaborative aspect, which is consequent on various professionals involved in sustaining the health of a population. Researches have shown that professional support is one factor that exercises huge influence on conformity to acceptable health practices by people (Gourlay, Birdthistle, Mburu, lorpenda \& Wringe 20I3; Muchacha \& Matsika, 20I7; Peng, Wang, Xu \& Wang, 2017). The issue of mother-to childtransmission in Nigeria is being marred with lots of barriers bordered on fear, stigma and discriminations associated with utilizing PMTCT services (Mepham et al., 20II; Osakwe, 2017; Theilgaard et al., 20II). Owing to these controversies, significant agencies and ministries of the Nigerian government have been expressing concerns in recent times $(\mathrm{FMH}, 2010$; NACA, 2016; PEPFAR, 2010). However, efforts aimed at encouraging uptake of PMTCT services would lack some level of influence without the inclusion of social workers. This is imperative on the roles social workers play in public health, with particular attention to areas of psychosocial determinants of health (International Federation of Social Workers [IFSW], 2008).

The success of PMTCT programmes demands a shift towards a more community based approach which calls for strong advocacy, enlightenment and community mobilization for improved information and awareness on HIV testing and utilization of PMTCT services (Arulogun, Adewole, Olayinka- Ali \& Adesina, 2007; Semali, Damian, Saronga \& Malamsha, 20I4). Hence, the importance of social workers. Social workers play many roles within NGOs, with the government health system or as part of their professional bodies, and to some extent as individual social change agents to promote PMTCT. They can also facilitate the provision of psychosocial support and strengthening community based support structures to support PLWHA; Facilitate community dialogues, awareness and male involvement to address stigma, discrimination and gender inequalities, address faith based objections to health care and advocacy/economic empowerment (Muchacha \& Matsika, 2017). They could help mothers protect their babies from HIV infection, encourage mothers to get treated with ARVs, counsel mothers to plan pregnancy carefully, support women in HIV care and support their families. They can also provide information on safe baby feeding and baby care. They also advocate and work with families and communities to support HIV positive women, their babies, and their families (Tanzania Social Work \& OVC initiative, 20I2). 


\section{Theoretical framework}

The study adopted the Health Belief Model as its theoretical framework. The model formed the basis of understanding why certain actions are taking per time in response to the health situation people finds themselves, especially in situations that require decision making such as the uptake of PMTCT of HIV. Originally developed as a systematic method to explain and predict preventive health behavior focusing on the relationship of health behaviors, practices and utilization of health services, the HBM has over the years been revised to include sick-role and illness behavior, and health motivation to reflect an individual's readiness to be concerned about health matters (Hochbaum, Kegels, \& Rosenstock, 1952; Ogden, 2004). Health behavior is any activity undertaken by a person who believes himself to be healthy for the purpose of preventing disease or detecting disease in an asymptomatic stage. Illness behavior is any activity undertaken by a person who feels ill, for the purpose of defining the state of his health and of discovering suitable remedy, while sickrole behavior is the activity undertaken by those who consider themselves ill for the purpose of getting well (Kasl \& Cobb, 1966; Rosenstock, 1974). The model assumes that a person's motivation to undertake a health behavior can be seen from three core perspectives: individual perceptions (perceived susceptibility and perceived severity); modifying behavior (demographic variables, perceived threat and cues to action); and likelihood to action (probability of appropriate health behavior and likelihood of taking recommended preventive health action). The HBM helps to understand the underlying factors that may influence the uptake of PMTCT of HIV services in Nigeria. This explains the choice of the variables in this study where HIV positive married women of reproductive age will likely go for the PMTCT services based on their perceived susceptibility and severity of the health condition on their children, and this is even more likely when they are aware of this services. However, in taking the expected action, some demographic variables such as place of residence, education and income may serve as modifying factors and perceived threats to taking the recommended positive health behaviours.

The applicability of HBM in this study would predict the likely actions that would promote the uptake of PMTCT among women of child bearing age in Anambra south all through the pregnancy care continuum starting from screening to adherence to recommendations. The uptake of PMTCT will be accepted if an individual perceives that the child is highly susceptible to HIV, that HIV is a severe health threat, that the benefits of preventing it are high, and that the costs of such action are comparatively low
(Ogden, 2004). The model also posited that some internal and external factors can affect health behaviors. Factors such as demographics, psychosocial, socio-demographic and structural variables can affect the individual's decisions in respect to the uptake of PMTCT, and other health seeking behaviors.

\section{Data sources and methods}

\section{Population and sampling}

This study was conducted in July 2016 and the study area is Anambra South Senatorial Zone which is one of the three senatorial zones in Anambra State. The state is located in the southeast geopolitical zone of Nigeria. Anambra state has a population of 4,4l8,032 as at 2006 national census. With an annual growth rate of $2.8 \%$, the population of the state as at 2017 when the study was done stood at 5,986,226. Women of reproductive age constitute about $25 \%$ of the population (National Population Commission, 2010). Prevalence rate of HIV/AIDS in Anambra State as at 2014 was $8.7 \%$ (Chukindi, 20I4), the fourth highest in the country (National Agency for Control of AIDS, 2016). Of the prevalence rate in the state, vertical transmission constituted about 4\% (Anambra State Ministry of Health, 2013). Anambra State Ministry of Health (2013) listed a total of 1485 health facilities in the state, out of which II 53 offered ANC services, with 63 of them providing ARVs for PMTCT and just one offers polymerase chain reaction (PCR) testing for early infant diagnosis (EID) of HIV.

Anambra is the gateway to the southeast from the western part of the country. It shares boundary with Delta and Rivers State; two prominent oil producing states in Nigeria with a large influx of local and international migrants. Oil exploration and migration in both states have been identified as promoters of risky sexual behaviours capable of spreading the prevalence of HIV. Anambra is also the most central of the 5 lgbo speaking southeast states as it is bounded to the north by Enugu and Ebonyi, to the east by Abia and to the south by Imo. Its location thus makes it a good choice for a study that can be generalized for the southeast. Also, the choice of Anambra South as the study area was because the biggest market in the whole West Africa, the Onitsha main market and the Nnewi Nkwo market which is also one of the biggest markets in Nigeria, is located there and this has the ability to attract people from different localities for different socio-economic activities. Thus, a lot of migrants come to trade, work and live in the zone and this, literature has shown, promote risky sexual behaviour that exacerbates the transmission of HIV. However, HIV women of reproductive age were adopted in this study because they are still within the age of conception and 
PMTCT services are offered before conception, and throughout pregnancy, labour and breastfeeding. This will help to maintain these women's health and stop their infants from acquiring HIV thereby reducing the spread of MTCT of HIV/AIDS.

Using purposive sampling technique, the researcher selected three hospitals from Anambra South Senatorial Zone, Anambra State. These three hospitals were selected on the ground that they were the only hospitals in Anambra South Senatorial Zone that offer antiretroviral drugs and prevention of mother - to- child transmission of HIV services to people living with HIV/AIDS. Thus, Nnamdi Azikiwe Teaching Hospital (NAUTH), Nnewi; Our Lady of Lourdes Hospital, Ihiala and Nnamdi Azikiwe Teaching Hospital, Trauma Center, Oba were selected.

\section{Data types and source}

Purposive sampling procedure was adopted to administer 515 questionnaires to HIV-positive women in these hospitals. The researchers administered 315 questionnaires in NnamdiAzikiwe Teaching Hospital, Nnewi; 100 questionnaires in Our Lady of Lourdes Hospital, Ihiala and 100 questionnaires in Nnamdi Azikiwe Teaching Hospital Trauma Center, Oba. The choice of 315 questionnaires in Nnamdi Azikiwe Teaching Hospital, Nnewi was based on the fact that it is a teaching hospital and also one of the oldest hospitals in Anambra State that offers services to people living with HIV/AIDS (PLWHA). The respondents were all HIV positive who were attending HIV clinics in the Heart-to-Heart centres in these hospitals. Heart-toHeart centres are designated places in major Nigerian hospitals that provide HIV related services to HIV patients. So all the respondents were met during periods they were attending clinics. Only questionnaires were used for eliciting the required information. This leaves an opportunity for another study that may adopt qualitative methods such as interviews.

In each of the selected hospitals, questionnaires were administered to HIV-positive pregnant women that were on antenatal services and also HIV-positive women of reproductive age that were not pregnant but were accessing antiretroviral (ARV) services in these hospitals. To ensure equal representation of HIV- positive women who were either pregnant or not, care was taken to ensure that the two groups were assigned equal number of questionnaires in the selected hospitals. Based on that, 157 HIV-positive pregnant women and I57 HIV-positive women of reproductive age that were not pregnant were given questionnaire in Nnamdi Azikiwe Teaching Hospital,
Nnewi. Simple random sampling (balloting) was used to assign the remaining questionnaire to HIV positive pregnant women (158) in Nnamdi Azikiwe Teaching Hospital Nnewi, thereby summing up the number of questionnaires that were administered to HIV positive women of reproductive age in Nnamdi Azikiwe Teaching Hospital, Nnewi to 315. In the same vein, questionnaires were administered to 50 HIV-positive pregnant women and 50 HIV-positive women of reproductive age that were not pregnant in Our Lady of Lourdes, Ihiala and Nnamdi Azikiwe Teaching Hospital Trauma Center, Oba respectively. Only respondents that were willing to participate in the study after due permission was obtained from the hospital authorities were used for the study. Available respondents were entered into the study until the desired sample size was reached.

\section{Variable description}

The study had five independent and two dependent variables. The independent variables include marital status, age, place of residence, educational level and wealth status while the dependent variables include awareness of intervention that can prevent mother to child transmission of HIV, and utilization of PMTCT services. The choice of these variables was as a result of its impact in health behaviours. PMTC services are provided to women that are married and/or of reproductive age, hence, the choice of marital status and age. Also, awareness, access and utilization of HIV services by these groups may be influenced by where they live (rural or urban), educational level (educated or not educated) and the level of their income (rich or poor). These variables explain the interplay of some factors in the awareness and utilization of PMTCT services among pregnant and married women.

\section{Data analysis}

The questionnaires were processed and analyzed with the Statistical Package for the Social Sciences (SPSS) version 20. Percentages and frequency tables were used to present the results, while five independent variables (marital status, age, place of residence, educational level and wealth status) were tested with (awareness of intervention that can prevent mother to child transmission of HIV, and utilization of PMTCT services) using Chi-square $\left(X^{2}\right)$ ) at $<0.05$ level of significance. The relationship between (marital status, age, place of residence, level of education, and wealth status) and (utilization of PMTCT of HIV services) were analyzed using binary logistic regression at $<0.05$ level of significant. 


\section{Ethical approval}

The ethical approval to conduct the study was sought from Research Ethics and Review Board of the University of Nigeria Teaching Hospital (UNTH) and Nnamdi Azikiwe University Teaching Hospital. The instrument and methodology used were reviewed and approval granted. Also permission to conduct part of the study at Our Lady of Lourdes hospital, Ihiala was sought, and granted by hospital authority. Respondents used in the study were well informed and consent obtained (signing a written informed consent or oral consent) before being included in the study. Confidentiality was assured and the study did not interfere with the routine activities of the participants or health workers at the centre.

\section{Results}

Socio demographic characteristics of respondents

The socio demographic characteristics of respondents show HIV positive mothers (5I5) were used for the study. Most of the respondents (79.0\%) were married, and traders. This distribution is illustrated in Table I.

Table I: Socio-demographic characteristics of respondents

\begin{tabular}{lll}
\hline $\begin{array}{l}\text { Variables } \\
\text { Marital status }\end{array}$ & $\mathrm{N}=515$ & $\%$ \\
$\begin{array}{l}\text { Single/divorced/widowed } \\
\text { Married }\end{array}$ & 108 & 21.0 \\
Education & 407 & 79.0 \\
Primary & 137 & \\
Secondary or Higher & 378 & 26.6 \\
\hline
\end{tabular}

More than $73 \%$ of the respondents had completed their secondary or higher education whiles a few $(26.6 \%)$ of the respondents had completed their primary education. Also, $52.0 \%$ of the respondents earned less than $\mathrm{N} 10,000$ as their monthly income. The respondents were all from Igbo ethnic group and self-identified as Christians.

Table 2: Utilization of PMTCT of HIV services

\begin{tabular}{lll}
\hline $\begin{array}{l}\text { Utilization } \\
\text { Can you rate the attitude of staff towards you when you went } \\
\text { for the PMTCT services }\end{array}$ & Frequency & Percentage (\%) \\
$\begin{array}{l}\text { Very friendly } \\
\text { Friendly }\end{array}$ & 228 & 44.3 \\
Not so friendly & 192 & 37.3 \\
Don't know & 75 & 14.6 \\
How close is the PMTCT centre to you & 20 & 3.8 \\
Very close & & 70 \\
Close & 40 & 8.8 \\
Far & 44 & 49.9 \\
Very far & 257 & 33.8 \\
How long do you normally stay befo99re you will be attended & 174 & \\
in PMTCT centre & & 78.4 \\
Less than I hour & 404 & 11.7 \\
One hour to two hours & 60 & 9.9 \\
Above two hours & 51 & \\
\hline
\end{tabular}

Considering utilization of PMTCT services, $44.3 \%$ of the respondents indicated that the attitude of the health workers towards them when they went for PMTCT services was very friendly. The finding could be attributed to the fact that these HIV positive mothers have been accessing PMTCT services, so they are now used to those health workers that attend to them. Or it could be as a result of policies in the workplace of the health workers that prevents them from stigmatizing those living with HIV/AIDS, so they don't have any option than to be friendly with them. On the issue of how close is the PMTCT centre to them $49.9 \%$ stated that the health centre is far from their place, and very far (33.8\%). Also, $78.4 \%$ of the respondents normally stay less than one hour at the PMTCT centres before they could be attended to. 
Table 3: Association between selected factors and awareness of intervention that can prevent mother to child transmission of HIV

\begin{tabular}{lcll}
\hline Variables & Aware & Not aware & \\
\hline & \% & $\%$ & Chi-square \\
\hline Marital status & & & \\
Single/divorced/widowed & 14.8 & 50.0 & 0.000 \\
Married & 85.2 & 50.0 & \\
Age & & & 0.119 \\
I5-34 & 72.0 & 80.0 & \\
$35-49$ & 28.0 & 20.0 & 0.233 \\
Place of residence & & & \\
Urban & 47.5 & 54.4 & \\
Rural & 53.5 & 45.6 & 0.805 \\
Educational level & & & \\
Primary or lower & 26.8 & 25.6 & \\
Secondary or higher & 73.2 & 74.4 & 0.054 \\
Wealth status & & & \\
Low & 49.6 & 63.3 & \\
Average & 43.1 & 30.0 & \\
High & 7.3 & 6.7 & \\
\hline Assocatis is & &
\end{tabular}

Association is significant at $p<0.05$

This section deals with explanation of association between selected factors and awareness of intervention that can prevent mother to child transmission of HIV. The analysis was done by cross tabulating selected independent variables with awareness of intervention that can prevent mother to child transmission of HIV. The result showed evidence of significant association between marital status, wealth status and awareness of intervention that can prevent mother to child transmission of HIV, the degree of awareness is moderate among the respondents. About $14.8 \%$ of respondents who were single/divorced/widowed reported being aware of intervention that can prevent mother to child transmission of HIV. Wealth status is another factor that showed significant association with awareness of intervention that can prevent mother to child transmission of HIV $(p<0.05)$. Surprisingly, higher proportion of HIV positive mothers with low wealth status $(49.6 \%)$ than those with high wealth status (7.3\%) reported being aware on intervention that can prevent mother to child transmission of HIV.

Table 4: Association between selected factors and utilization of PMTCT services

\begin{tabular}{lccc}
\hline Variables & Utilized & Not utilized & \\
\hline & \% & \% & Chi-square \\
\hline Marital status & 30.2 & 3.4 & 0.000 \\
Single/divorced/widowed & 69.8 & 96.6 & \\
Married & 70.7 & 78.5 & 0.056 \\
Age & 29.3 & 21.5 & \\
I5-34 & & & 0.037 \\
$35-49$ & 52.1 & 42.4 & \\
Place of residence & 47.9 & 57.6 & 0.391 \\
Urban & & & \\
Rural & 27.8 & 24.3 & \\
Educational level & 72.2 & 75.7 & \\
Primary or lower & & & 0.614 \\
Secondary or higher & 53.3 & 49.7 & \\
Wealth status & 40.2 & 41.8 & \\
Low & 6.5 & 8.5 & \\
Average & & & \\
High & &
\end{tabular}

Association is significant at $\mathrm{p}<0.05$ 
Out of the five selected explanatory variables included in the bivariate analysis, marital status, age and place of residence were significantly associated $(p<0.05)$ with utilization of PMTCT services. About $30.2 \%$ of single/divorced/widowed reported the use of PMTCT services, while $3.4 \%$ did not utilized it. Also, about $70.7 \%$ of the respondents within the ages of I5-34 utilized PMTCT services as compare to
$29.5 \%$ of those within the ages of 35-49 years. Surprisingly, the magnitude of HIV positive women who reported the use of PMTCT services were almost close in urban and rural area. $52.1 \%$ and $47.9 \%$ of HIV positive women in rural area respectively utilized PMTCT services. Association between place of residence and utilization of PMTCY services was significant $(p<0.05)$.

Table 5: Binary logistic regression model predicting utilization MTCT of HIV services in Anambra South Senatorial Zone

\begin{tabular}{|l|l|l|l|}
\hline Predictors & Beta Coefficient & Level of Significance & Odds Ratio \\
\hline Marital Status & 2.499 & $.000^{*}$ & 12.175 \\
\hline Age & -.386 & .100 & .680 \\
\hline Place of Residence & .402 & $.043^{*}$ & 1.495 \\
\hline Level of Education & .165 & .474 & 1.179 \\
\hline Wealth Status & .010 & .999 & 1.100 \\
\hline
\end{tabular}

*Significant at $\mathrm{P}<0.05$

Source: Authors' Computation, 2018

Using the five socio-demographic characteristics of the respondents as independent variables, their relationship with the level of utilization of PMTCT in the study areas was assessed using the binary logistic regression analysis. Being single, aged less than 35 , residing in rural areas, having a level of education below secondary school, and earning less than $\mathrm{N} 50,000$ a month constituted the reference categories in the analysis. With a Beta Coefficient of 2.499 and 0.402 respectively, marital status and place of residence recorded a positive relationship as predictors of PMTCT utilization. In other words, being married or aged above 35 years increases the chances of utilizing PMTCT by 2.499 and 0.402 units respectively. The odds ratios for both independent variables, as shown in Table 5, are given as 12.175 and I.495. Both variables were also statistically significant $(P<0.05)$. Age, level of education and wealth status did not significantly predict PMTCT utilization in the study area.

\section{Discussion}

The study investigates the factors that determine the utilization of prevention mother to child transmission of HIV services in Anambra South Senatorial Zone of Anambra state.

Among the socio-demographic variables, age of mothers was significantly associated with utilization of PMTCT services. Older women (35-49) were $29.3 \%$ less likely to utilize PMTCT service as compared to younger ones (15-24). The underlying reason for this outcome may be associated with the willingness of the younger women in Anambra to embrace change due to their increased awareness of the incidence of HIV compare to the older women. Other reasons that may be attributed to this finding are exposure and cultural orientation. Younger women in Anambra appear more technologically exposed as they embrace social media and other media platforms including traveling and associating with others allowing them the opportunity to know more about HIV and PMTCT. This finding is consistent with the study conducted in Sebeta Town, Central Ethiopia, in which older age groups (25-34) were less likely to utilize PMTCT services as compared to those younger (I5-24) [Merga, Woldemichael \& Dube, 2016] and in Gondar, north-west Ethiopia, in which 15-24 aged mothers were 5.6 more likely to accept PMTCT in the ANC clinics (Malaju \& Alene, 20I2).

Also, in a related study by Meeme (2013) in Uganda, age group 25-29 was also significantly associated to PMTCT utilization with $(p=0.002)$. Furthermore, another study conducted in Ethiopia on prevention of mother to child transmission of HIV/AIDS services indicated that mothers in their late age of pregnancy (34-44years) were less likely to utilize PMTCT services as compared to women in their earlier ages (Feyera, Megerssa, Legessa \& Hailemichael, 2017) This finding also agrees with the study conducted in Jimma zone, southwest Ethiopia, in which pregnant mothers who were in the earlier 15 to 29 years of age utilized PMTCT services more likely than their counterparts in the later age category (Hussein, Jira, \& Girma, 20I I). But a study conducted in Debre Markos, north-west Ethiopia, reported that socio-demographic variables showed no association (Isegay, Edris \& Meseret, 2013) and another study conducted in Nigeria showed teenagers were 3 times less likely to utilize the service when compared with the older women (Amoran, Salami \& Oluwole, 20I2). This could be that younger and older women may differ in their 
perceived risk of HIV and understanding of the importance of HIV testing. It could also be that younger and older women may differ in their perceived risk of HIV, understanding of importance of HIV testing and utilization of PMTCT services as espoused in the theoretical framework. Just like Semali, Damian, Saronga \& Malamsha (20l4) in a study they conducted in Tanzania opined that Mother to child transmission of HIV (MTCT) control goal is achievable when all pregnant mothers test for HIV and collect the results enabling timely eligibility and access to anti-retroviral therapy (ART). So, while this is the case in other parts as reported by the authors, the situation is peculiar in Anambra where acceptance and utilization is age conditioned as in many cases the older women are more culturally sensitive and tied to the old ways of doing things compare to the younger women.

Another socio-demographic variable which had association with PMTCT service utilization in this study was mother's place of residence. Mothers from urban area were $52.1 \%$ more likely to utilize PMTCT services than $47.9 \%$ of those from rural area. This is in agreement with the study conducted in Uganda where mothers from urban areas utilize PMTCT services than those from rural areas (Taaka, 20I2). A related study by Feyera, Megerssa, Legessa and Hailemichael (2017), observed that mothers from rural settings were less likely to utilize PMTCT services as compared to their urban counterparts. This finding is also in line with that of the study conducted in Western Amhara region Ethiopia, which showed that women who lived in urban settings utilized HIV testing more than those who lived in rural settings (Worku, 2007). This could be explained by the fact that women in urban settings have better accesses to ANC/PMTCT services, better education, information and awareness about the services when compared to those in rural settings. Also important is the fact that in Anambra State of Nigeria, major and functional social amenities and services including HIV related services are concentrated in the urban areas which confer more opportunities to urban dwellers more than the rural dwellers whose access to these services are limited.

Furthermore, another socio-demographic variable which had association with PMTCT service utilization in the study area was mother's marital status. Mothers who are married were $69.8 \%$ more likely to utilize PMTCT services than their counterparts who are single. Mothers who are married have two fold more likely to have their partners involved in PMTCT services than those who are not married. In Anambra, there are socio-cultural attachments associated with marriage before child bearing, and marriage is used as a platform for measuring 4783 responsibility of both male and female as well as determining the resource distribution of the local communities to her members. Therefore, it is a thing of pride for women to get married before getting pregnant, and this may inform why married women in this study are more prone to utilizing PMTCT than the unmarried as they are in a better position to receiving social supports that helps to boost their confidence. The findings of this study are implicated in the assumptions of the theoretical framework. The theoretical framework assumes that a person's motivation to undertake a health behavior can be viewed from three core perspectives: individual perceptions of the health situation (perceived susceptibility and perceived severity); factors that modify behavior (demographic variables, perceived threat and cues to action); and likelihood to action (probability of appropriate health behavior and likelihood of taking recommended preventive health action). Findings has shown that though the respondents may be interested in taking preventive health actions such as the uptake of PMTCT services, however, some factors such as the age of the mothers, the place of their residence and sociocultural influences as well as marital status influenced their health seeking behaviours.

\section{Conclusion}

The study revealed that attitude of the health workers to HIV women of reproductive age accessing PMTCT services was friendly, PMTCT centre was far from these women and that these women spent less than one hour before they can be attended to in PMTCT centre. Also, the study has provided empirical evidence that age, place of residence and marital status are associated with the utilization of PMTCT services in Anambra South Senatorial Zone. As such, there is urgent need for government, non-governmental organization, social workers and healthcare providers to rise to their responsibilities in encouraging HIV women of reproductive age to utilize PMTCT services. This can be done through the introduction of effective health education though public enlightenment, seminars, workshops and sensitization programmes to eradicate the risk of MTCT of HIV/AIDS and curtail the spread of HIV/AIDS and losses of mothers and infants incurred as a result of non-utilization of PMTCT services in order to achieve African Union Agenda $3(\mathrm{AU})$ which is geared towards healthy, well-nourished and long life spams. Also, there is the need for government and policy makers to make and implement policy that will focus on educating HIV positive women on the need to utilize PMTCT of HIV services and the danger of not accessing the services. Increased awareness creation by the government,

http://aps.journals.ac.za 
non-governmental organization and social workers about HIV/AIDS and the PMTCT programme using different channels and through churches as well as multiple channels of communication at grassroots level is encouraged to provide wider access to information concerning PMTCT of HIV services. In addition, the researchers recommended that ongoing health talks should be provided to pregnant women attending antenatal clinics beyond what they are told the day they came for booking in the health facility. All aspects of transmission from mother-tochild should be emphasized during the health talks to promote a better understanding of PMTCT. This is important considering the facts that some of these heath facilities have PMTCT centre but do not educate the HIV positive women of reproductive age properly on the important of utilizing PMTCT services.

\section{Conflict of interest}

The authors declare no conflict of interest.

\section{Funding}

None.

\section{References}

Abajobir, A. A., \& Zeleke, A. B. (20I3). Knowledge, attitude, practice and factors associated with prevention of mother to child HIV/AIDS among pregnant mothers attending antenatal clinic in Hawassa referral hospital, South Ethiopia, J. AIDS Clin Research, 4(6). Retrieved from http://dx.doi.org//0.4|72/2155-61/3.10002I5

Adetokunboh O.O \& Oluwasanu M. (20/6). Eliminating mother-to-child transmission of the human immunodeficiency virus in sub-Saharan Africa: The journey so far and what remains to be done. Journal of infection and public health, 9(4),396-407.doi.org/10.1016/j.jiph.2015.06.010

Agboghoroma, C.O., Sagay, S.A., \& Ikechebelu, J. I. (20I3). Nigeria prevention of mother to child transmission of human immunodeficiency virus program: the journey so far. Journal of HIV and Human Reproduction, I(I), I-7.

Agudu, N. A. S., Ramadhani, H. O., Isah, C., Anaba, U., Erekaka, S., Osuala, C. F., Galafanci, H., \& Charurat, M. (2017). The impact of structured mentor mother programs on 6month postpartum retention and viral suppression among HIV positive women in rural Nigeria: a prospective cohort study. Acquired Immune Deficiency Syndrome, 75(2), |73-|81.

Amoran, O. E., Salami, O. F., \& Oluwole, F. A. (20I2). A comparative analysis of teenagers and older pregnant women in the utilization of prevention of mother to child transmission
(PMTCT) services in, Western Nigeria. BMC International Health and Human rights, I2(I3).

Arisegi, S. A., Awosan, K. J., Abdulsamad, H., Adamu, A. H., Isah, M. B., \& Mora, S.

Knowledge and practices regarding prevention of mother-to-child transmission of HIV among health workers in primary healthcare centres inSokoto, Nigeria. International STD Research \& Review, 6(3), I-9.

Balogun, F. M., \& Owoaje, E. T. (2015). How acceptable are the prevention of mother to child transmission (PMTCT) of HIV services among pregnant women in a secondary health facility in Ibadan Nigeria? Annals of Ibadan Postgraduate Medicine, 13(1), 17- 22.

Cohen, J. (20/8). Nigeria has more HIV-infected babies than anywhere in the world. It's a

distinction no country wants. Retrieved from http://www.sciencemag.org/news/20|8/06/nigeria -has-more-hiv-infected-babies-anywhere-world-its-distinction-no-country-wants

Eze, A. U., Aniwada, E. C. (20/6). Prevention of mother to child transmission of HIV; knowledge, attitude, practice and determinants among pregnant women in Abia State, Nigeria. International STD Research Reviews, 4(2), I-I4.

Ezeanolue, E. E., Obiefuna, M. C., Yang, W., Obaro, S. K., Ezeanolue, C. O., et al. (20|3). Comparative effectiveness of congregation-versus clinic based approach to prevention of mother to child HIV transmission: study protocol for a cluster randomized controlled trial. Implement Sci., 8(62).

Federal Ministry of Health. (2010). National Scale up Plan towards Elimination of Mother to Child Transmission of HIV in Nigeria 20I0-20I5. FmoH Abuja.

Feyera, A., Megerssa, B. Legessa, D. \& Hailemichael, F.(2017). Prevention of mother to child transmission of HIV/AIDS services utilization and associated factors among selected public health facilities in Ethiopia. Academic Journals, 8(I), I-I3

Global health learning organization (20I7). Motherto-Child Transmission of HIV. Retrieved from https:/www.globalhealthlearning.org/course/moth er-child-transmission

Gourlay, A., Birdthistle, I., \& Wringe, A. (20/3). Barriers and facilitating factors to the uptake of antiretroviral drugs for prevention of mother-tochild transmission of HIV in sub-Saharan Africa: a systematic review. Journal of the International AIDS Society, I6(I).

Hamdela, B., Zekiewos, F., \& Workneh, T. (20I4). Knowledge on mother to child transmission and utilization of services designed to prevent mother to child transmission of HIV/AIDS 
among pregnant women in Hossana Town, Southern Ethiopia. Journal of AIDS \& Clinical Research, 5(396).

Hussein, M., Jira, C. \& Gima, B. (20I I). Assesment of effective coverage of HIV prevention of pregnant mother to child transmission services in Jimma Zone, South West Ethiopia. Ethiop. J. Health Sci., $2 I(I), I-7$

Hochbaum G., Kegels S., \& Rosenstock I. (1952). Health Belief Model. United States Public Health. Retrieved from academia.edu.

Ibrahim, U., Mohammed, M., \& Umar, I. F. (20I6).

Assessment of PMTCT knowledge and

utilization among pregnant mothers attending

Abubakar Tafawa Balewa University Teaching

Hospital (ATBUTH) Bauchi, Nigeria. Sky Journal of Medicine and Medical Sciences, 4(I), I-6.

International Federation of Social Workers.

(2008). IFSW policy statement on health.

Retrieved

from

http://www.ifsw.org/p3800008l.html.

Iwelunmor J, Ezeanolue E. E, Airhihenbuwa C.O, Obiefune M.C, Ezeanolue C.O \& Ogedegbe G.G (20|4). Socio-cultural factors influencing the prevention of mother-to-child transmission of HIV in

Nigeria: a synthesis of the literature. BMC Public Health, 14:77I,

http://www.biomedcentral.com/I47I$458 /|4 / 77|$.

Joint United Nations Programme on HIV/AIDS (2008)

Global report: UNAIDS report on the global AIDS epidemic. UNAIDS, Geneva.

Kalule-Sabiti, I., Amoateng, A. Y, \& Ngake M. (20I4). The Effect of Socio-demographic Factors on the Utilization of Maternal Health Care Services in Uganda. APS; 28(I): 5I5-525.

Kasl S. V \& Cobb S. (1966). Health behavior, illness behavior and sick-role behavior. Archives of Environmental Health: An International journal I, I2(2), 246-266 and II, I2(4), 53 I-54I.

Malaju, M.T. \& lene, G.D. (20|2). Assessment of utilization of provider-initiated HIV testing and counseling as an intervention for prevention of mother to child transmission of HIV and associated factors among pregnant women in Gondar town, NorthWest Ethiopia, BMC Public Health, 12, 226

Meeme, M. (20/3). Factors influencing utilization of Prevention of Mother to Child Transmission (PMTCT) of HIV/AIDS in UGANDA. Retrieved from http://hdl.handle.net// 0570/2067

Mepham, S., Zondi, Z., Mbuyazi, A., Mkhwanazi, N., \&Newel, M. L. (20I I). Challenges in PMTCT antiretroviral adherence in northern KwaZuluNatal, South Africa. AIDS Care, 23(6), 74I-7.
Merga, H., Woldemichael, K. \& Dube, L. (20/6). Utilization of prevention of mother to child transmission of HIV services and associated factors among antenatal care attending mothers in Sebeta Town, Central Ethiopia. Advances in Public Health.

Mfrekemfon, P. I., \& Rimande-Joel, R. (20I5). Mother-to-child transmission (MTCT) of Human Immunodeficiency Virus (HIV). IOSR Journal of Humanities and Social Sciences, 20(3), 3338.

Michael, O. D., \& Ogbodo, U. C. (20I3). Implications for factors affecting prevention of mother to child transmission of HIV programs in university teaching hospitals in Anambra state. Texila Journal, 5(I).

Moses, A., Chama, C., Udo, S., \& Omotora, B. (2008). Attitude and practice of ante-natal attendees towards prevention of mother to child transmission (PMTCT) of HIV infection in a tertiary health facility, Northeast-Nigeria. The Internet Journal of Third World Medicine, 8(I).

Muchacha, M., \& Matsika, A. (2017). Understanding the role of social workers in the promotion and uptake of prevention of mother-to-childtransmission of HIV in Zimbabwe. Retrieved from https://www.researchgate.net/publication/318562 816

National Agency Control of Aids. (2016). Fact sheet: prevention of mother to child transmission (PMTCT), 2016. NACA, Abuja. Retrieved from https://naca.gov.ng/fact-sheet-prevention-motherchild-transmission-pmtct-2016

National agency for the control of AIDS (20I2). Nigeria Global Response Country Progress Report. NACA, Abuja.

National Agency for the Control of AIDS (2018). Nigeria Has More HIV-Infected Babies Than Anywhere In The World. It's A Distinction No Country Wants. Press release on internationalworkers day 2018. Retrieved from https://naca.gov.ng/press-release-internationalworker-day-2/

National Population Commission (NPC) and ICF Macro (2009). Nigeria Demographic and Health Survey 2008: Key Findings. NPC and ICF Macro, Calverton, Maryland, USA.

Ogden J (2004). Health psychology: A text book ( $3^{\text {rd }}$ ed). England; Open University press -McGraw-Hill Education. pp 24-27.

Osakwe, F. (2017). HIV/AIDS: Elimination of motherto-child transmission still challenged. Features.

Retrieved from https://t.guardian.ng/features/health/hivaidseliminatio-of- mother-to-childtransmission-still-challenged http://aps.journals.ac.za 
Peng, Z.,Wang, S., Xu, B., \& Wang, W.(2017). Barriers and enablers of the prevention of mother-to-child transmission of HIV/AIDS program in China: a systematic review and policy implications. International Journal of Infectious Diseases, 55, 72-80. https://doi.org//0.1016/j.ijid.2016.12.028

President's Emergency Plan for AIDS Relief. (2010). Prevention of Mother-to-child transmission of HIV: Expert Panel Report and Recommendations to the U.S. Global AIDS coordinator. Retrieved from https://www.pepfar.gov

Rosenstock I. (1974). The Health Belief Model and Preventive Health Behavior. Health Education Monographs, 2, (4).

Semali I, Damian J.M, Saronga P.H \& Malamsha D. (20I4). Factors associated with HIV testing and receiving results during antenatal care in Tanzania. African Population Studies, 28(2) Supplement. Retrieved from http://aps.journals.ac.za.

Taaka, J. (20/2). Factors affecting utilization of prevention of mother to child transmission (PMTCT) in Busia District, Uganda. Retrieved from http://hdl.handle.net//0570/3 |47

Tanzania Social Work \& OVC Support Initiative (20I2). Para Social Worker II: Practice Skills to Intervene with Vulnerable Children and Families in Special Circumstances. Retrieved from https://www.aiha.com/wp-content

The African Union Commission (20l4). AGENDA 2063: The Africa we want DRAFT DOCUMENT. 2013, year of Pan- Africanism and African renaissance. OAU/AU 50th Anniversary Solemn Declaration.

Theilgaard, Z. P., Katzenstein, T. L., Chiduo, M. G., Pahl, C., Bygbjerg, I. C. Gerstoft J.,et. al. (20II). Addressing the fear and consequences of stigmatization- a necessary step towards making HAART accessible to womwn in Tanzania: a quantitative study. AIDS Res Ther., 8(28).

Tobore, O., (20I3). Alarming: Nigeria leads the world in number of children contracting HIVUN report. Premium Times. Retrieved from http://www.premiumtimesng.com/...//39706alarming-nigeria-leads-the-world

Tsegay, G., Edris, M. \& Meseret, S. (20II). Assessment of voluntary counseling and testing service utilization and associated factors among Debre Markos University Students, North West Ethiopia: a cross-sectional survey in 201 I. BMC Public Health, I 3(I), 243

UNICEF (20I7). Prevention of Mother to Child Transmission (PMTCT). Geneva, Switzerland.

Retrieved from https://www.unicef.org/supply/index_42855.html

WHO, UNAIDS \& UNICEF (2009). Towards universal access: scaling up priority HIV/AIDS interventions in the health sector, September 2009 Progress report. WHO, Geneva, Switzerland.

Worku T (2007). Utilization of PMTCT services among pregnant woman in western Amhara Region Ethiopia. MPH thesis

World Health Organization (2010). Towards universal access: scaling up priority HIV/AIDS interventions in the health sector. Geneva, Switzerland

World Health Organization. (20I I). Progress report: 201 I: Global HIV/AIDS response. Geneva, Switzerland: 